\title{
Doğal Adsorbent Kullanarak Sulardan Maxilon Golden Yellow'un Renk Gideriminde Ortam Koşullarının İncelenmesi
}

\author{
Ezgi GÜNEŞ GÜRDAL ${ }^{1}$, Erkan KALIPCI ${ }^{2 *}$
}

\section{Öz}

Bu çalışmada; Maxilon Golden Yellow GL EC 400\% (MGY-GE) boyasının Nevsehir (Türkiye) Cin Deresi dere yatağına ait doğal kil (DK) ile sulu çözeltilerden gideriminde ortam koşulları araştırılmıştır. Adsorpsiyon koşulları; MGY-GE boyasının $100 \mathrm{mg} / \mathrm{L}$ konsantrasyonunda, $2.0 \mathrm{~g}$ adsorbent kullanılarak, farklı temas süresi, çözelti pH'ı ve sicaklığında incelenmiştir. Adsorpsiyon sürecinin Langmuir ve Freundlich izotermlerine uygunlukları araştırılmıştır. MGY-GE boyası gideriminde kullanılan DK için deneysel verilerin Langmuir izoterm modeline uyum gösterdiği bulunmuştur. Doğal kil için en yüksek renk giderimi; pH 8'de (\%98.44) 300 dakika ve $25^{\circ} \mathrm{C}^{\prime}$ de elde edilmiştir. Sonuç olarak; doğal kilin MGYGE boyasının sulu çözeltiden gideriminde kulanılabileceği ve bu doğal kilin yüksek tutma kapasitesine sahip olduğu belirlenmiştir. Düşük maliyetli ve bol miktarda bulunan doğal kil, MGY-GE boyasının giderimi için diğer adsorbentlere tercihen kullanılabilir.

Anahtar Kelimeler: Doğal kil, Maxilon golden yellow, Renk giderimi, Adsorpsiyon.

\section{Examination of Ambient Conditions of Maxilon Golden Yellow for Color Removal From Waters by Using Natural Adsorbent}

\begin{abstract}
In this study, ambient conditions for removal of Maxilon Golden Yellow GL EC 400\% (MGY-GE) dye from aqueous solutions by using natural clay (NC) of Nevsehir (Turkey) Cin stream bed were investigated.Adsorption conditions were examined at $100 \mathrm{mg} / \mathrm{L}$ concentration of MGY-GE dye using $2.0 \mathrm{~g}$ adsorbent, different contact time, solution $\mathrm{pH}$ and temperature.The fitting of adsorption process with respect to Langmuir and Freundlich isotherms was examined. Experimental data for NC used in MGY-GE dye removal has been found to adapt to the Langmuir isotherm model.The highest color removal was obtained during 300 minutes and $25{ }^{\circ} \mathrm{C}$ at $\mathrm{pH} 8(98.44 \%)$ for natural clay. As a result; it was indicated that natural clay can be used for the removal from aqueous solution of MGY-GE dye has high adsorption capacity for dye. Abundantly in nature and low-cost clay can be used for the removal of MGY-GE dye in preference to other adsorbents.
\end{abstract}

Keywords: Natural clay, Maxilon golden yellow, Color removal, Adsorption.

\footnotetext{
${ }^{1}$ Nevşehir Hacı Bektaş Veli Üniversitesi, Çevre Mühendisliği Bölümü, Nevşehir, Türkiye, ezgiguness@gmail.com

${ }^{2}$ Giresun Üniversitesi, Harita Mühendisliği Bölümü, Giresun, Türkiye, erkankalipci@gmail.com
}

${ }^{1}$ https://orcid.org/0000-0002-1629-9495 ${ }^{2}$ https://orcid.org/0000-0002-1908-5468 


\section{Giriş}

Tekstil, kauçuk, kağıt, deri, plastik, ilaç, gıda, boya fabrikaları vb. endüstriyel tesislerde yaygın olarak boyar maddeler kullanılmaktadır. Bu sektörlerden kaynaklanan boyalı atıksular, mutajen ve kanserojen özelliklere sahip olduğundan insan ve çevre sağlığı açısından toksik riskler taşımaktadır. Ayrıca, bu tür renkli atıksular deşarj edildiği sucul alanlarda güneş ışığının bentik organizmalara nüfuzunu azaltarak fotosentetik aktiviteyi engellemenin yanısıra görüntü kirliliğine de sebep olmaktadır (Öden ve Küçükçongar, 2017; Kalıpcı, 2016; Ngulube ve ark., 2017). Bu nedenle; son yıllarda sulardan boyaların giderimi için yapılan bilimsel çalışmalarda artışlar yaşanmaktadır (Li ve ark., 2020; Tara ve ark., 2020; Wu ve ark., 2020; Kadhom ve ark., 2020; Xia ve ark., 2020). Yapılan bilimsel çalışmalar incelendiğinde, arıtım yöntemlerinin etkili ve maliyetinin düşük olması, kullanılacak adsorbentlerin ise ucuz ve doğada kendiliğinden bulunması gerektiği belirtilmektedir (Ngulube ve ark., 2017; Kalıpcı, 2019). Tekstil atıksularından renk giderimi için hem biyolojik hem de fiziksel/kimyasal yöntemler kullanılmaktadır. Tekstil endüstrisinde boyar madde içeren atıksuların geleneksel atıksu arıtma yöntemleri kullanılarak arıtılması çok zordur, çünkü boyalar 1şık ve oksitleyici ajanların varlığında stabildir ve aerobik sindirime dirençlidir. Eski yöntemler; çoğu boyaların biyolojik olarak parçalanamayan doğası nedeniyle çok başarılı olmamıştır. Literatür incelendiğinde; kogaülasyon, kimyasal oksidasyon, flotasyon, ters ozmoz, fenton prosesi, elektrofenton prosesi, ozonlama, biyolojik arıtma prosesi, adsorpsiyon gibi birçok fiziksel, kimyasal ve biyolojik yöntemlerle atıksulardan renk giderim metotları uygulanabildiği görülmektedir (Sun ve Yang, 2003; Kuleyin ve Aydin, 2011; Juang ve ark., 1997; Doğan ve ark., 2009; Kalıpcı ve ark., 2016). Kullanılan bu metotlardan kimyasal ve elektro-kimyasal çöktürme, fenton ve elektro-fenton proseslerinde, toksik ve ağır metal içerikli kimyasal çamurlar oluşmaktadır. Bu çamurların bertarafı arıtma maliyetini ciddi oranda arttırmaktadır. Ozonlama ise yüksek maliyetli ve kalifiye eleman gerektiren bir süreçtir. Bunun yanısıra ozon seçiçi olmayacağı için atıksu içerisindeki bütün kirleticilerle reaksiyona girme eğilimindedir. $\mathrm{Bu}$ da yeterli arıtma verimi için ozon ihtiyacını arttırarak, arıtım maliyetinin artmasına neden olmaktadır. Biyolojik prosesler kullanılarak genellikle çok az miktarda renk giderimi yapılabilmektedir. Bu yöntemler arasında en pratik ve ekonomik olanı adsorpsiyon ile renk giderim metodudur (Gürses ve ark., 2002, Gupta ve Suhas, 2009). Nitekim, Elmoubarki ve ark. (2015) tarafından yapılan adsorpsiyon çalışması ile ucuz ve kolay elde edilebilir olan Moroccan doğal kili, sulu çözeltiden tekstil boyalarının uzaklaştırılması için verimli bir şekilde kullanılmıştır. Uyar (2012) ise yapmış olduğu çalışmasında, alginat ve kili birleştirerek kompozit bir adsorbent oluşturup metilen mavisi boyasının sulu çözeltiden \%95 verim ile giderimini sağlamıştır. 
Yapılan bu çalışmada; atıksularda yaygın bir kirletici parametre olarak bulunan MGY-GE boyasının doğada bol miktarda bulunan Nevşehir yöresine ait doğal kil kullanılarak sulu çözeltiden adsorpsiyon ile gideriminde ortam koşulları incelenmiştir. Adsorpsiyon kinetikleri ve adsorpsiyonu etkileyen parametreler araştırılarak, sulu çözeltiden MGY-GE boyar maddesinin gideriminde alternatif arıtım malzemesi olarak kullanılabilirliğinin araştırılması amaçlanmıştır.

\section{Materyal ve Metot}

Çalışmada adsorbent olarak kullanılan doğal kil, Nevşehir ili Avanos İlçesine yaklaşık 5 km uzaklıkta bulunan Cin deresinin dere yatağından temin edilmiştir. $1 \mathrm{~N} \mathrm{H}_{2} \mathrm{SO}_{4}$ ile yıkandıktan sonra doğal kil, distile su (Minipure, Destup) ile yıkanarak nötral pH seviyesine getirilmiştir. pH’ı nötr'e getirilen doğal kil 10 dakika süresince 5000 rpm hızda santrifüj (NÜVE, NF 200) edilerek çöktürülmüştür. Etüvde (JSR, JSOF-100) 48 saat, $105{ }^{\circ} \mathrm{C}$ sıcaklıkta kurutma işlemine tabi tutulmuştur. Malzemenin tanecik boyutu önemli olduğu için, kurutulan doğal killer, 150-200 $\mu$ m'lik eleklerde elenmiş ve kesikli adsorpsiyon deneylerinde kullanılmak üzere desikatörde muhafaza edilmiştir.

Çalışmada tekstil endüstrisinde yoğunlukla kullanılan bir boyar madde olması ve literatürde fazla çalışılmamış olması nedeniyle MGY-GE boyar maddesi kullanılmıştır. Ticari olarak piyasadan temin edilen MGY-GE boyası, sulu bir çözelti hazırlamak için daha fazla saflaştırma olmaksızın 100 mg/L olacak şekilde stok çözelti hazırlanarak kullanılmıştır. MGY-GE boyasının kimyasal yapısı Şekil 1'de, kalibrasyon eğrisi ise Şekil 2' de verilmiştir.

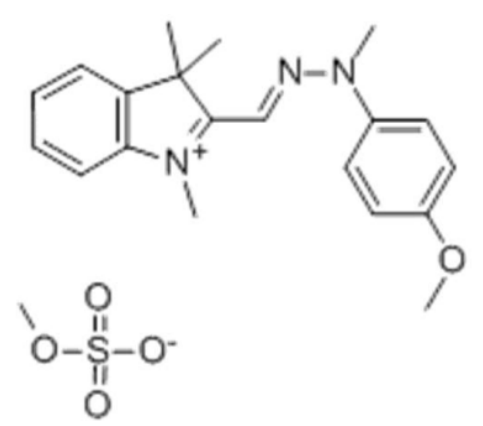

Şekil 1. MGY-GE boyasının kimyasal yapısı (URL-1, 2021). 


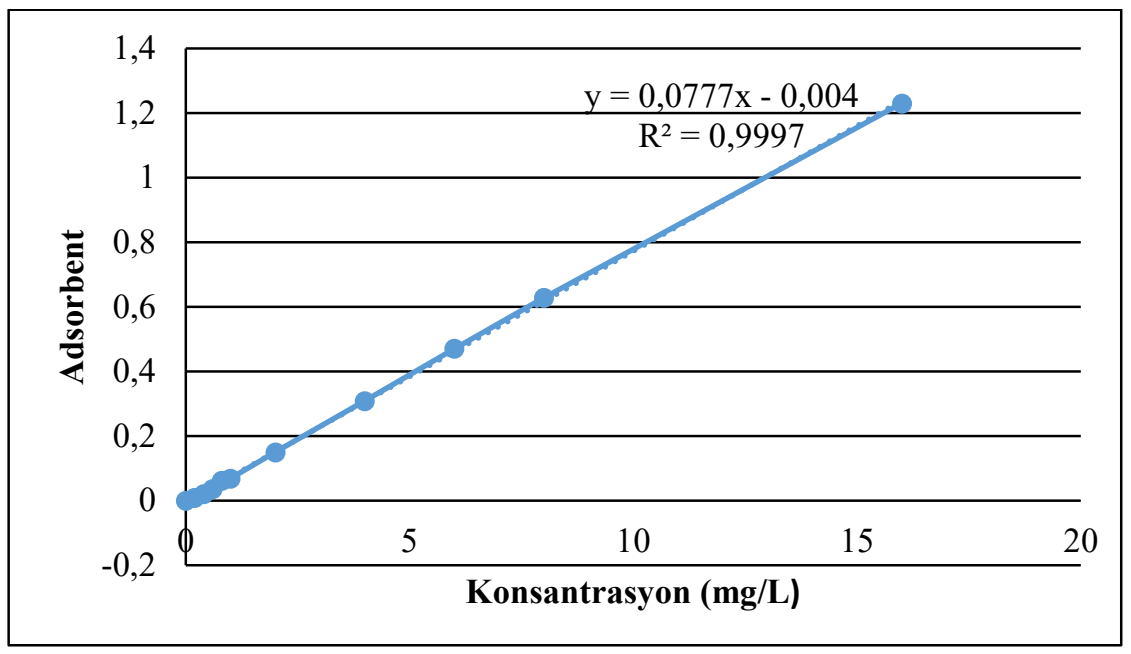

Şekil 2. MGY-GE boyasının kalibrasyon eğrisi.

MGY-GE çözeltilerinin tamamı ultra saf su (MP Minipure Destup) ile hazırlanmıştır. Farklı araştırmacılar tarafından yapılan çalışmaların (Adeyemo ve ark., 2017; Ouardi ve ark., 2015) incelenmesi sonucunda adsorbent miktarının $2.0 \mathrm{~g}$ ile maksimum giderim sağlayacağına karar verilmiştir. $\mathrm{Bu}$ nedenle, kilin sulu çözeltiden MGY-GE boyasının gideriminde ki uygun koşulları belirlemek için $2.0 \mathrm{~g}$ tartılarak $100 \mathrm{mg} / \mathrm{L}$ 'lik hazırlanan $100 \mathrm{~mL}$ MGY-GE çözeltisine eklenmiştir. Deneysel çalışma, farklı pH'larda (2-12), farklı temas sürelerinde (5-300 dk) ve farklı sıcaklıklarda $\left(25-60{ }^{\circ} \mathrm{C}\right)$ yapılmıştır. Çözeltinin $\mathrm{pH}$ '1, multi parametre ölçer cihazı (Hach Lange, HD30d) kullanılarak $0.1 \mathrm{~N}$ Hidroklorik asit ve $0.1 \mathrm{~N}$ Sodyum hidroksit ile ayarlanmıştır. Adsorbe edilen MGY-GE boya miktarının tespiti için adsorpsiyon sürecinin tamamlanmasından sonra 5 dakika 2400 rpm hızda santrifüj (NÜVE, NF 200) işlemi ile çözeltilerden katı maddelerin çökmesi sağlanmıştır. Santrifüj işleminden sonra 0,45 $\mu \mathrm{m}$ 'lik membran filtreler (Millipore Corp., Bedford, Mass.) kullanılarak numune adsorbentten ayrılmıştır. Ölçümlerde Thermo Scientific Aqua Mate Plus UVVIS model spektrofotometri kullanılmıştır.

Dengede adsorbe edilen MGY-GE miktarı; $q$ e $\left(\mathrm{mg}^{-1}\right)$ aşağıda verilen denklemle belirlenmiştir:

$q_{e}=V\left(C_{0}-C_{e}\right) / W$

Formülde, mg/g cinsinden adsorpsiyon kapasitesi, $\mathrm{q}_{\mathrm{e}} \mathrm{ile}$; $\mathrm{mg} / \mathrm{L}$ cinsinden başlangıç ve denge konsantrasyonları, $\mathrm{C}_{0}$ ve $\mathrm{C}_{\mathrm{e}}$ ile; boyarmadde çözeltisinin $\mathrm{mL}$ içindeki hacmi $\mathrm{V}$ ile; $\mathrm{mg}$ cinsinden kullanılan adsorbentin kütlesi ise $W$ ile ifade edilmiştir (Kayacan, 2007).

Freundlich adsorpsiyon izotermi, çok katmanlı adsorpsiyonun heterojen bir adsorban yüzeyinde gerçekleştiği varsayımıyla elde edilen aşağıdaki denklemlerle ifade edilir (Freundlich, 1906).

$$
\log q_{e}=\log K_{f}+(1 / n) \log C_{e}
$$


Formülde Freundlich sabiti $\mathrm{K}_{\mathrm{f}}(\mathrm{mg} / \mathrm{g})$ ile, Freundlich katsayısı n ile gösterilmiştir. Doğal adsorbanların düşük enerji heterojenitesine sahip adsorban yüzeyindeki aktif bölgelerini $n$ parametresi tarif etmektedir. Bu parametre aynı zamanda adsorpsiyon yoğunluğunun da göstergesi olup 1 ile 10 arasındaki değer, iyi bir adsorpsiyon sürecini ifade etmektedir. Şayet n, 1'den küçükse, adsorpsiyonun kimyasal olduğunu büyük ise fiziksel olduğunu göstermektedir (Fytıanos ve ark., 2000).

Langmuir izotermi ise aşağıdaki denklem ile ifade edilir.

$$
\frac{\mathrm{C}_{\mathrm{e}}}{\mathrm{q}_{\mathrm{e}}}=\frac{1}{\mathrm{Q}_{0} b}+\frac{1}{\mathrm{Q}_{0}} \mathrm{C}_{\mathrm{e}}
$$

$\mathrm{Q}_{0} \quad\left(\mathrm{mg} \mathrm{g}^{-1}\right)$ ve $b\left(\mathrm{~L} \mathrm{mg}^{-1}\right)$ adsorpsiyon kapasitesi ve adsorpsiyon oranı ile ilgili Langmuir sabitleridir, $q_{e}$ dengede adsorbe edilen MGY-GE miktarıdır $\left(\mathrm{mg} \mathrm{g}^{-1}\right)$ ve $C_{e}$ ise sıvı faz denge konsantrasyonudur (mg L-1) (Weber ve Digiano,1996).

\section{Bulgular ve Tartışma}

\section{1. pH'ın Etkisi}

pH ve giderim verimleri incelendiğinde; Şekil 3'de görüldüğü üzere $5 \mathrm{dk}$ adsorpsiyon süresince MGY-GE giderim verimi en yüksek, $25^{\circ} \mathrm{C}$ 'de $\mathrm{pH} 12$ 'de (\%96.44), $35^{\circ} \mathrm{C}$ 'de $\mathrm{pH} 8$ 'de (\%97.10), 45 ${ }^{\circ} \mathrm{C}$ 'de $\mathrm{pH} 4$ 'te $(\% 93.28)$ ve $60{ }^{\circ} \mathrm{C}$ 'de $\mathrm{pH} 12$ 'de (\%93.06) gerçekleşmiştir.

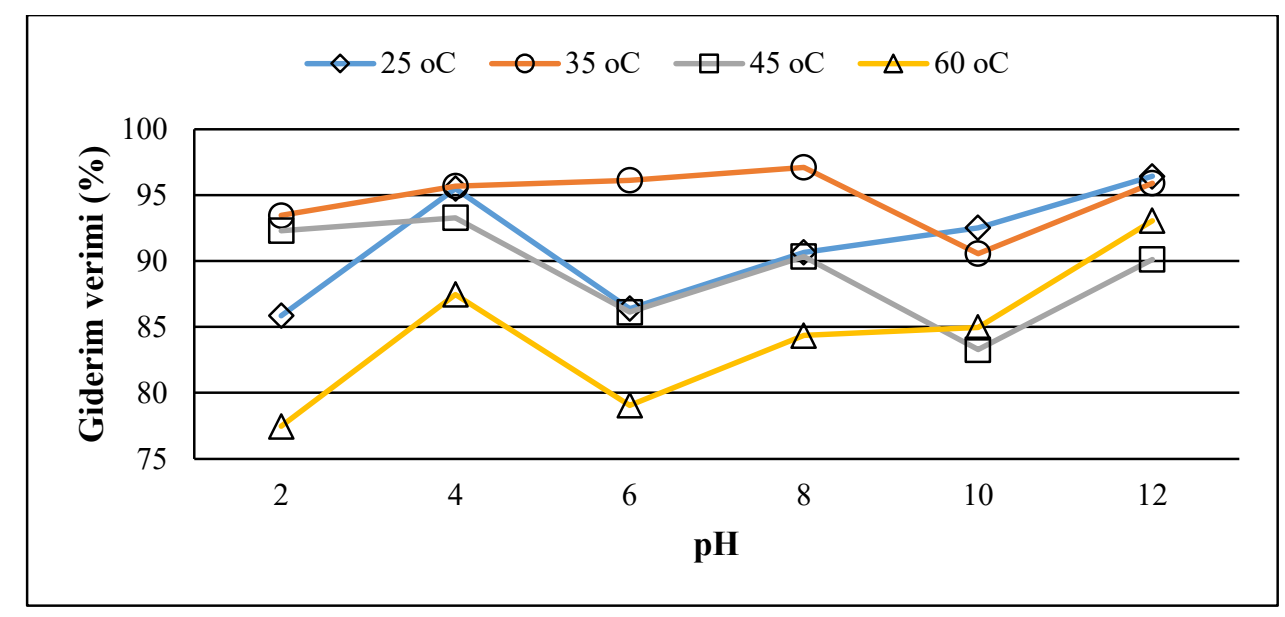

Şekil 3. Başlangıç $\mathrm{pH}$ ’ ve sıcaklığın $\mathrm{t}=5 \mathrm{dk}$ için renk giderim verimine etkisi. 


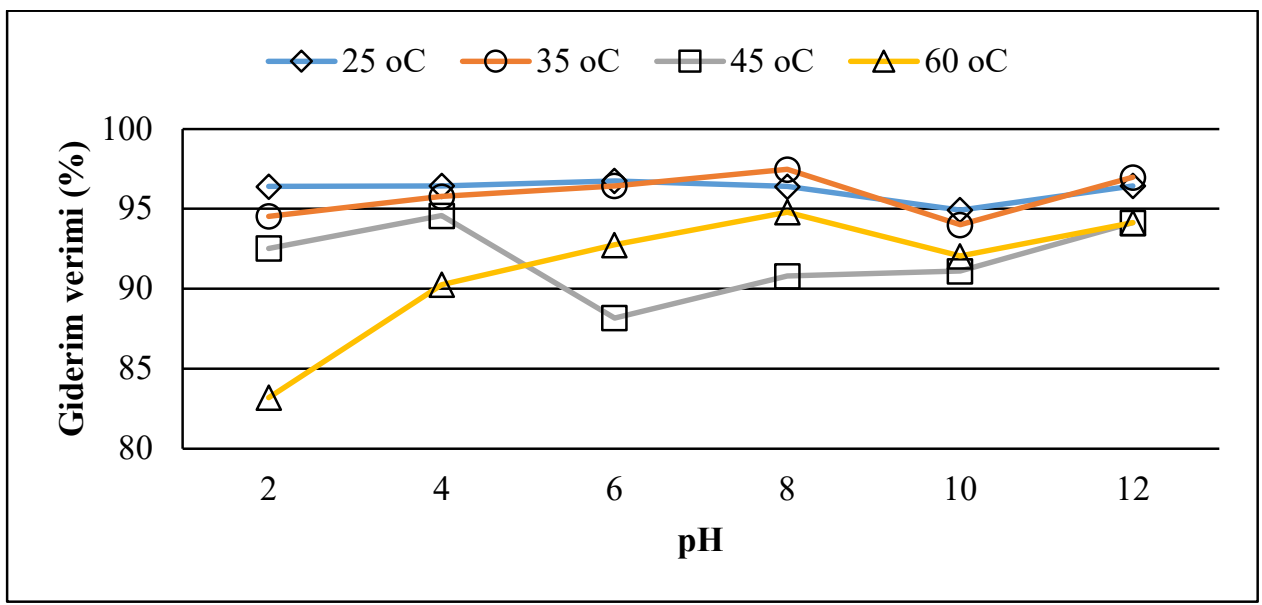

Şekil 4. Başlangıç pH’ı ve sıcaklığın $\mathrm{t}=60 \mathrm{dk}$ için renk giderim verimine etkisi.

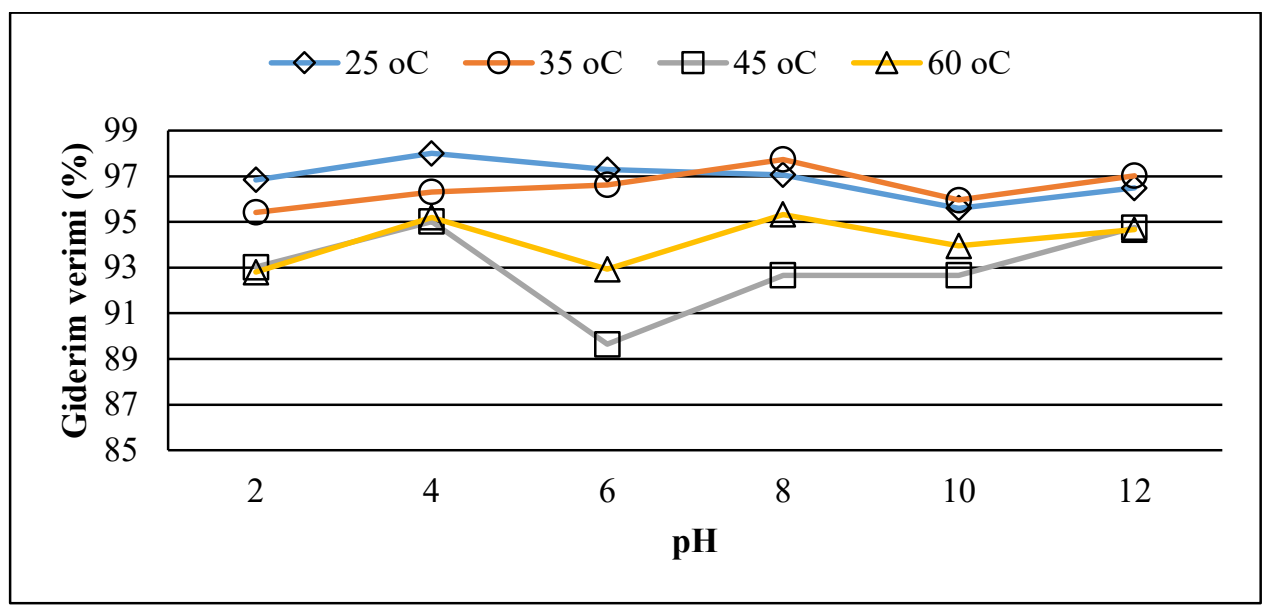

Şekil 5. Başlangıç $\mathrm{pH}$ ’1 ve sıcaklığın $\mathrm{t}=120 \mathrm{dk}$ için renk giderim verimine etkisi.

Deneysel çalışmalar; $60 \mathrm{dk}$ ve $120 \mathrm{dk}$ adsorpsiyon için renk giderimde en yüksek verimin sırasıyla $25^{\circ} \mathrm{C}$ ve pH 6'da (\%96.75), $25^{\circ} \mathrm{C}$ ve pH 4'te (\%97.99) olduğunu göstermiştir (Şekil 4, Şekil $5)$.

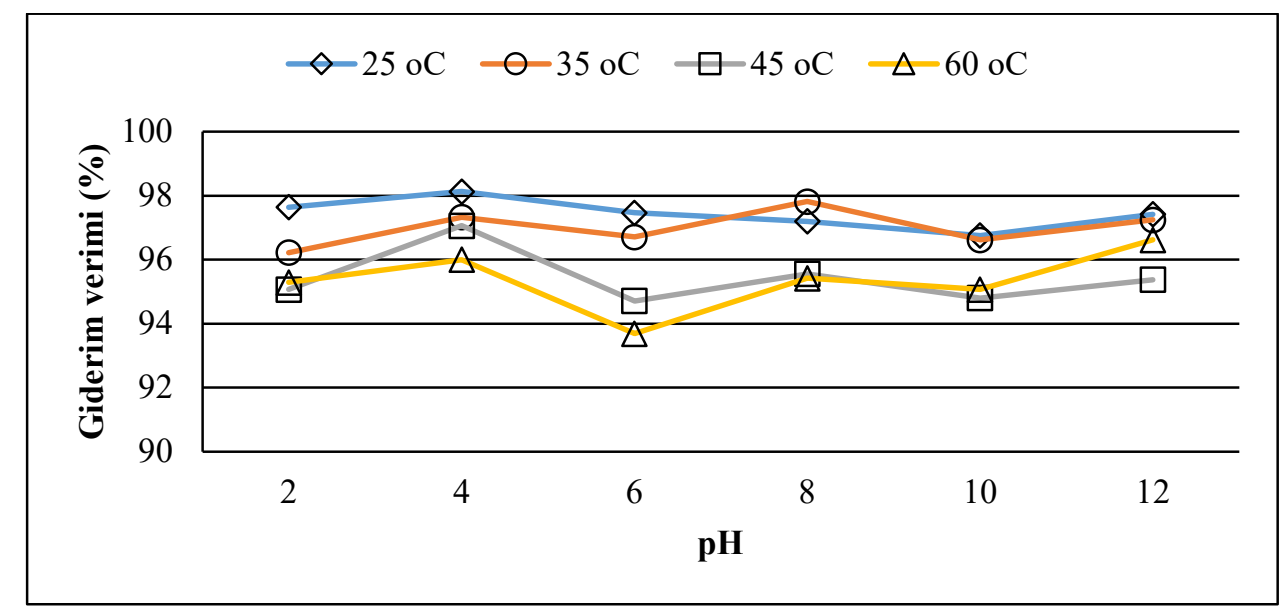

Şekil 6. Başlangıç pH'ı ve sıcaklığın t= $240 \mathrm{dk}$ için renk giderim verimine etkisi. 


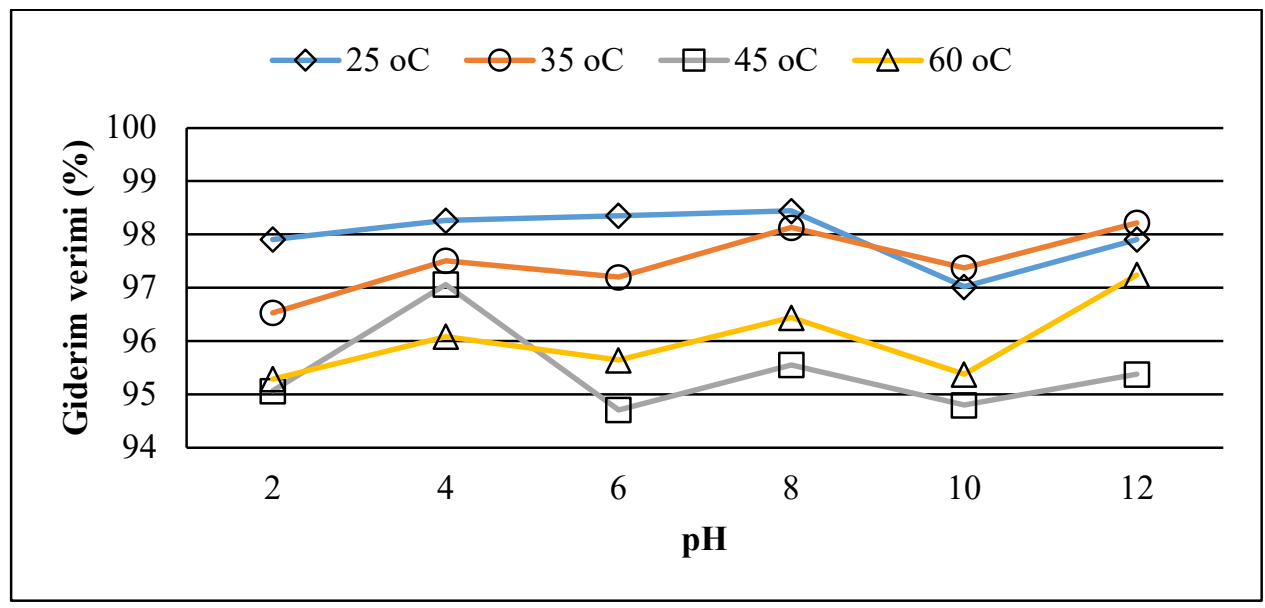

Şekil 7. Başlangıç Ph'1 ve sıcaklığın t= $300 \mathrm{dk}$ için renk giderim verimine etkisi.

$\mathrm{pH}$ ve giderim verimleri $240 \mathrm{dk}$ 'llk adsorpsiyon için incelendiğinde renk giderim verimi en yüksek $25{ }^{\circ} \mathrm{C}$ için $\mathrm{pH} 4$ 'te (\%98.13), $300 \mathrm{dk}$ 'llk adsorpsiyon sürecinde ise $25{ }^{\circ} \mathrm{C}$ için pH 8 'de (\%98.44) olduğunu göstermiştir (Şekil 6, Şekil 7). DK kullanılarak MGY-GE gideriminde temas süresi arttıkça renk giderim verimliliğinin arttığı, optimum sıcaklıkların $25{ }^{\circ} \mathrm{C}$ ve $35{ }^{\circ} \mathrm{C}$ 'de gerçekleştiği belirlenmiştir. Giderimde en yüksek verime, $25{ }^{\circ} \mathrm{C}$ sıcaklık, $\mathrm{t}=300$ dakika ve pH 8 koşullarında (\%98.44) ulaşılmıştır.

\subsection{Adsorpsiyon sıcaklığının etkisi}

Doğal kil kullanılarak MGY-GE'nin farklı pH'lardaki giderim etkisi Şekil 8-Şekil 13'de gösterilmiştir. Şekil 8'de görüldüğü üzere pH 2'de DK için en ideal adsorpsiyon sıcaklığının $25^{\circ} \mathrm{C}$ (\%97.90)'de gerçekleştiği belirlenmiştir. Şekil 9 incelendiğinde en düşük renk gideriminin $60{ }^{\circ} \mathrm{C}$ sıcaklıkta gözlendiği, pH 4'de ise DK için en ideal adsorpsiyon sıcaklığının $25{ }^{\circ} \mathrm{C}$ (\%98.26) olduğu belirlenmiştir. MGY-GE boyasının DK ile gideriminde adsorpsiyon sıcaklığının artması durumunda pH 2 ve pH 4'te olumsuz bir etki oluştuğu belirlenmiş olup boya ve DK arasındaki etkileşimin zayıf kaldığı söylenebilir. Bunun sebebinin, düşük pH ortamında $\mathrm{H}^{+}$iyonlarının yüzeysel etki alanında bulunan boşlukları kaplaması ve MGY-GE boyasının tutulma kapasitesini engellemesi ile açıklanabilmektedir. Genel olarak adsorpsiyon, sıcaklık artışıyla artarken, sıcaklığın düşmesiyle azalır. Bunula birlikte adsorpsiyon prosesi, ekzotermik bir proses ise adsorpsiyonun büyüklüğü azalan sıcaklıkla artacaktır (Uysal ve Kereci, 2016). 


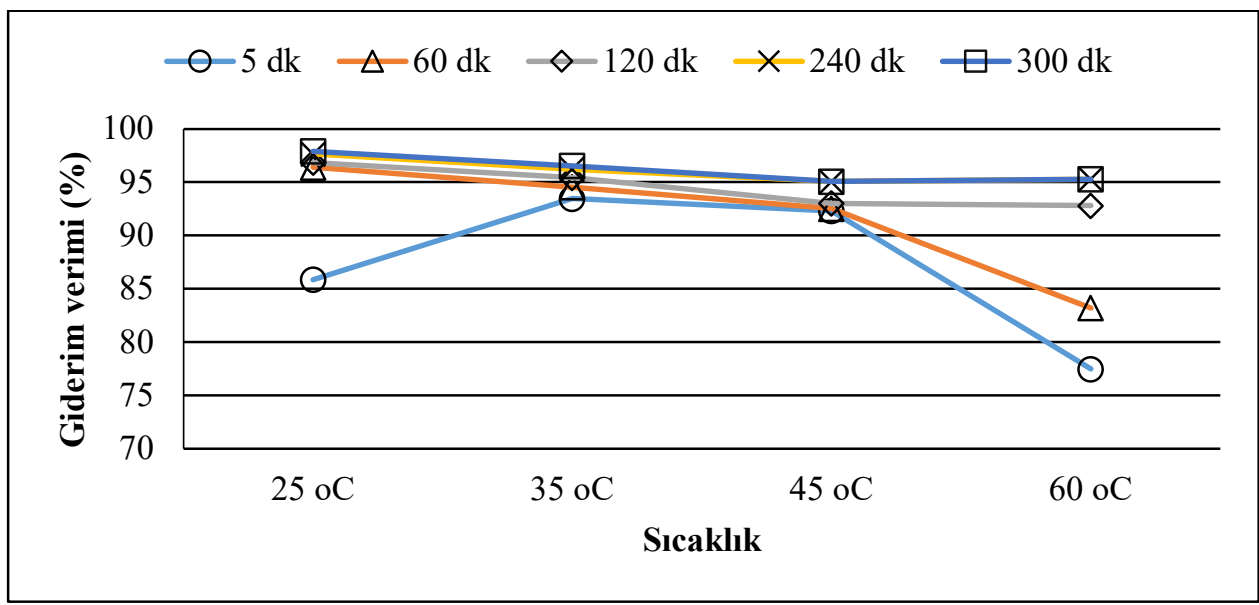

Şekil 8. Farklı sıcaklık ve temas sürelerinin $\mathrm{pH}$ 2'deki renk giderim verimine etkisi.

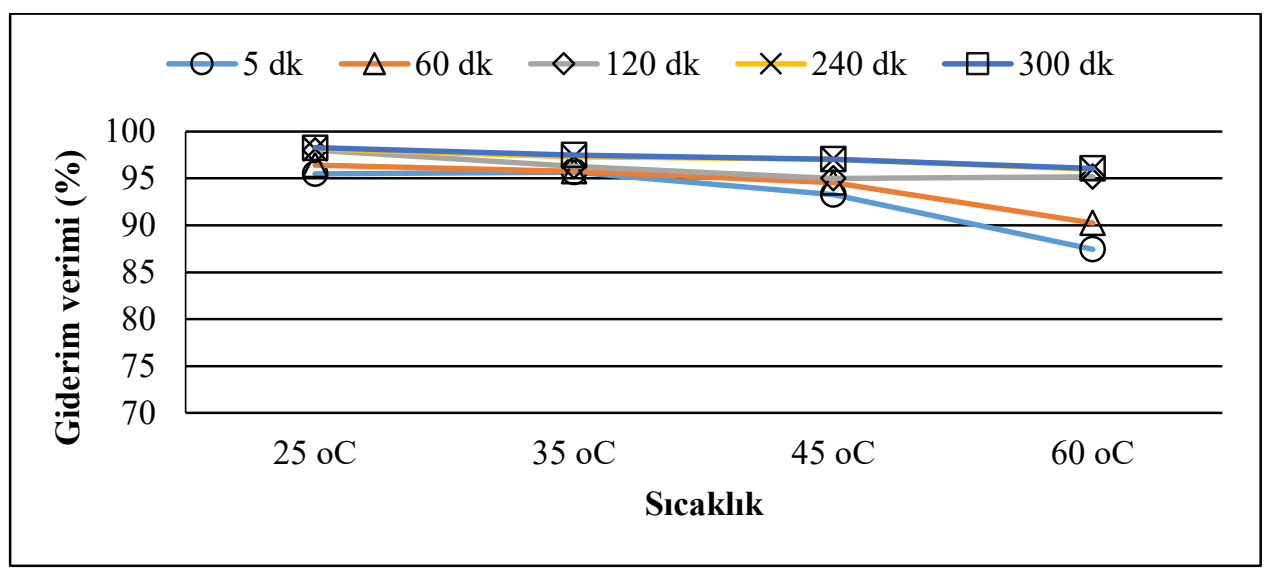

Şekil 9. Farklı sıcaklık ve temas sürelerinin pH 4'deki renk giderim verimine etkisi.

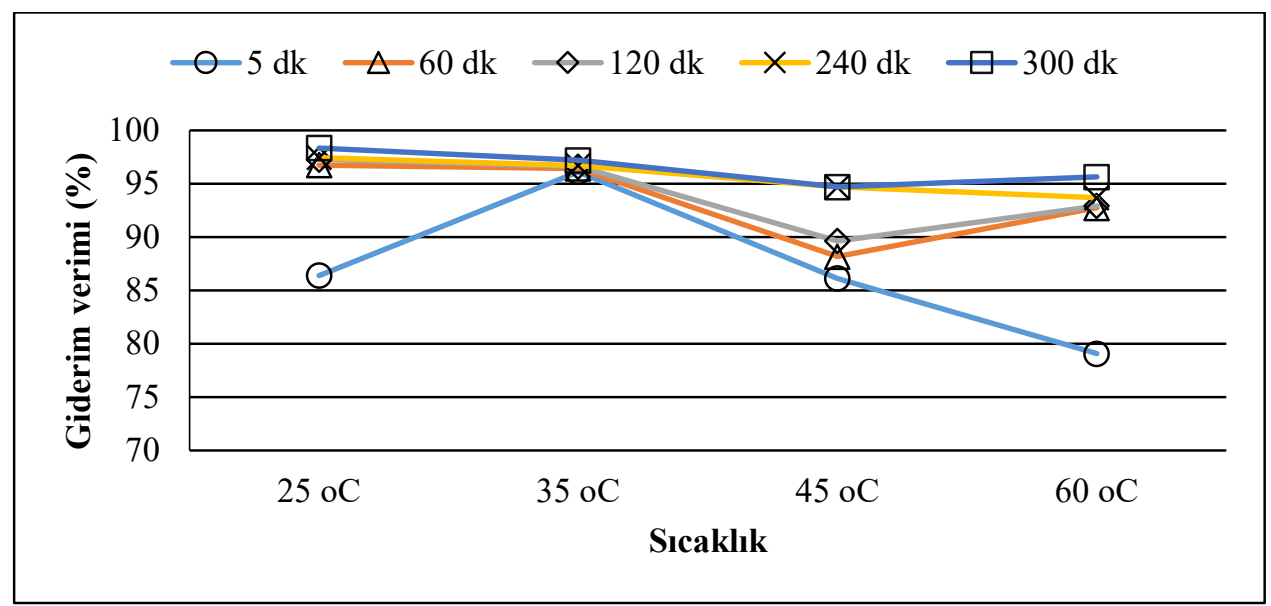

Şekil 10. Farklı sıcaklık ve temas sürelerinin pH 6'daki renk giderim verimine etkisi. 


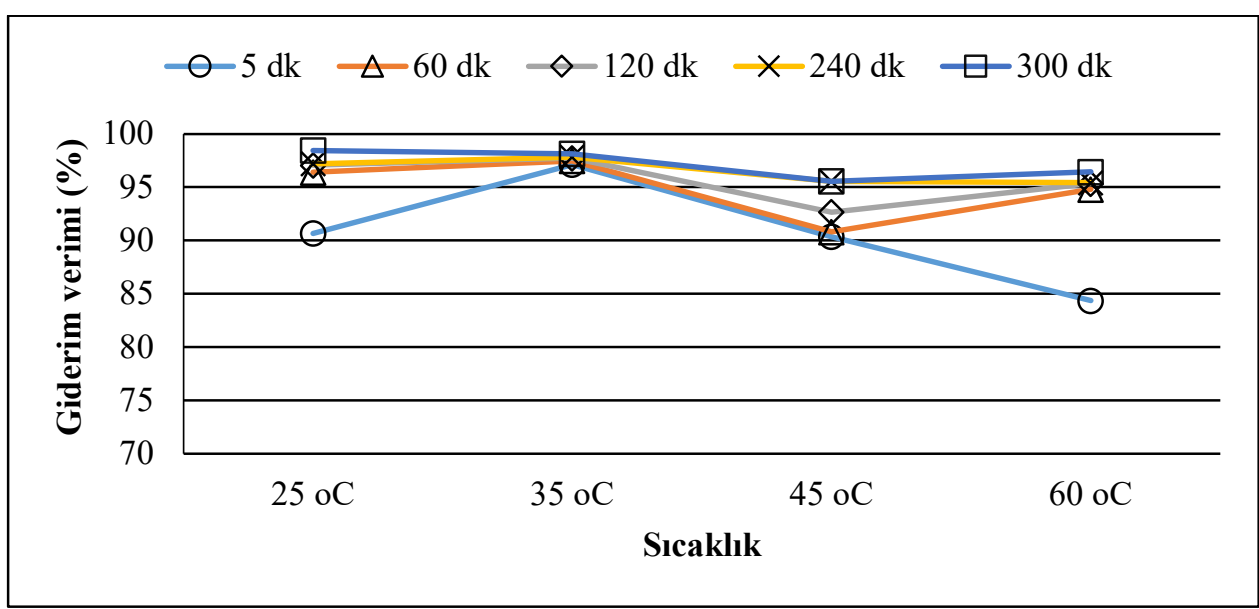

Şekil 11. Farklı sıcaklık ve temas sürelerinin $\mathrm{pH}$ 8'daki renk giderim verimine etkisi.

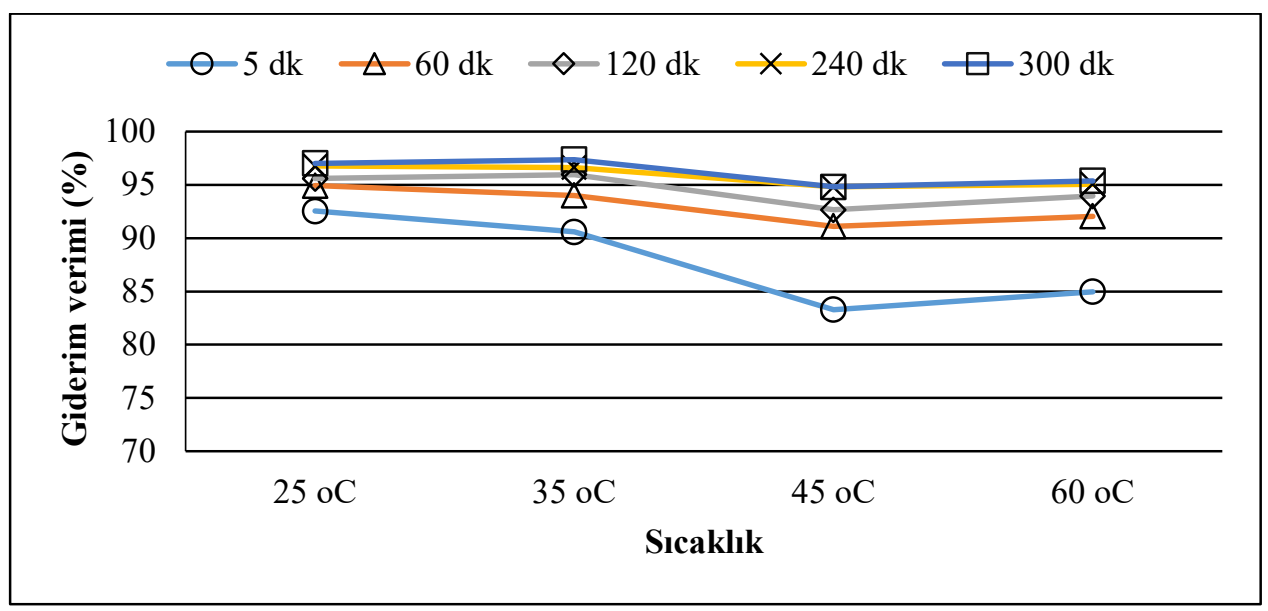

Şekil 12. Farklı sıcaklık ve temas sürelerinin $\mathrm{pH}$ 10'daki renk giderim verimine etkisi.

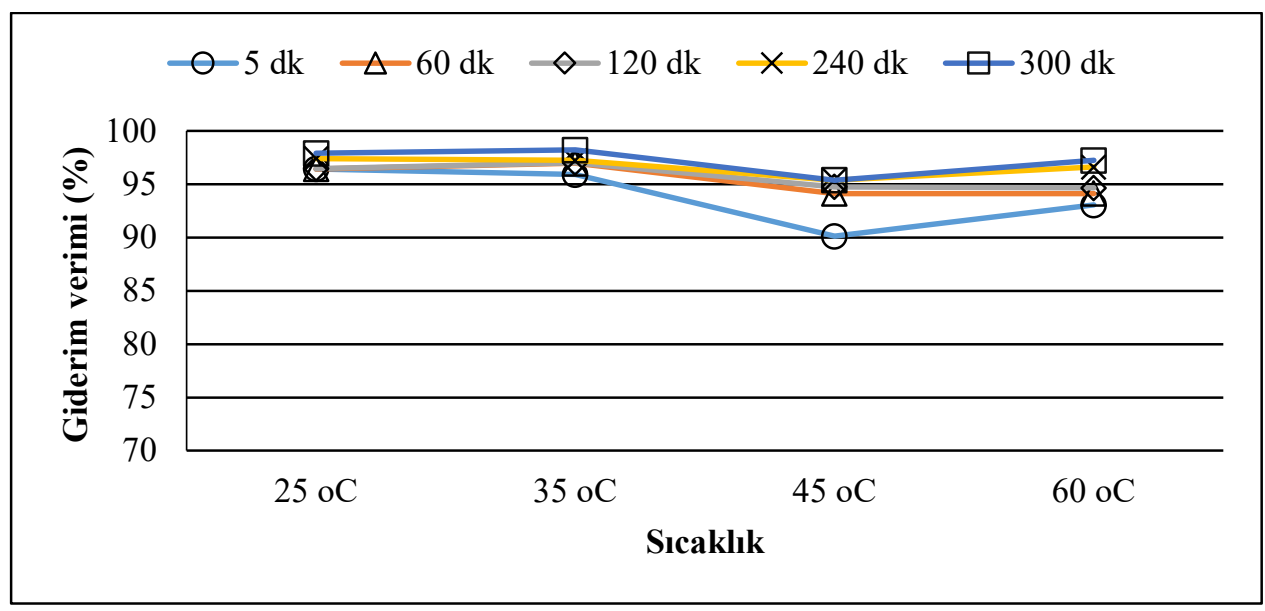

Şekil 13. Farklı sıcaklık ve temas sürelerinin $\mathrm{pH}$ 12'deki renk giderim verimine etkisi.

Şekil 10 ve Şekil 11 'de görüldüğü üzere; pH 6'da $45^{\circ} \mathrm{C}$ sicaklıkta, $\mathrm{pH} 8$ 'de $45^{\circ} \mathrm{C}$ ve $60{ }^{\circ} \mathrm{C}$ sıcaklıklarda renk giderim verimleri düşmüştür. Başlangıç pH’ı 6 ve pH 8 için giderim verimlerinin sırasıyla \%98.35 ve \%98.44 olması nedeniyle en uygun sıcaklık $25{ }^{\circ} \mathrm{C}$ olarak tespit edilmiştir. Başlangıç pH'ı 10'da DK için en uygun adsorpsiyon sıcaklığı $35^{\circ} \mathrm{C}$ 'de $(\% 97.37)$, pH 12 'de ise $35^{\circ} \mathrm{C}$ 
(\%98.21)'de belirlenmiş olup $45^{\circ} \mathrm{C}$ sıcaklıkta ise en düşük giderim verimleri elde edilmiştir. Genel bir değerlendirme yapıldığında MGY-GE boyası için yüksek renk giderimi, çözelti pH 8' de iken yani bazik ortamda $25^{\circ} \mathrm{C}$ 'de $\% 98.44$ ile gerçekleşmiştir. $\mathrm{pH} 10$ ve $\mathrm{pH} 12$ değerlerinde ise, renk giderimi en yüksek $35^{\circ} \mathrm{C}$ 'de elde edilmiştir (Şekil 12 ve Şekil 13). Çalışmada, $25^{\circ} \mathrm{C}$ sıcaklıkta pH arttıkça giderim veriminde bir artış gözlenmiştir. Yapılan benzer bir çalışmada da pH değerinin artması ile negatif yük yoğunluğu ve negatif yüklü yüzeyin arttığı bunun etkisi ile de adsorpsiyon kapasitesinde artış olduğu belirtilmiştir (Mingfei and Peng, 2009). Yine benzer bir etki, sulu bir çözeltiden bentonit üzerine bazik boya adsorpsiyonu (Gok ve ark., 2010) ve metil violet boyasının perlit ile adsorpsiyonu (Dogan ve Alkan, 2010) için rapor edilmiştir.

\subsection{Adsorpsiyon temas süresinin etkisi}

Adsorpsiyon temas süresinin etkisi DK için Şekil 14-Şekil 19'da verilmiştir. Buna göre sıcaklık değerlerinin ve $\mathrm{pH}$ değerlerinin tamamında temas süresinin artmasıyla birlikte MGY-GE boyası giderim veriminin de artış gösterdiği belirlenmiştir. Deneysel çalışmadaki renk giderimi ise en yüksek 300. dakikada elde edilmiştir. Kaykığlu ve Güneş'in (2014) yapmış olduğu sulu çözeltilerden renk gideriminin araştırıldığı benzer bir çalışmada da temas süresinin arttıkça adsorpsiyonla giderim veriminin arttığını ve belli bir süre sonunda bu değerin bir dengeye ulaştığı bildirilmiştir.

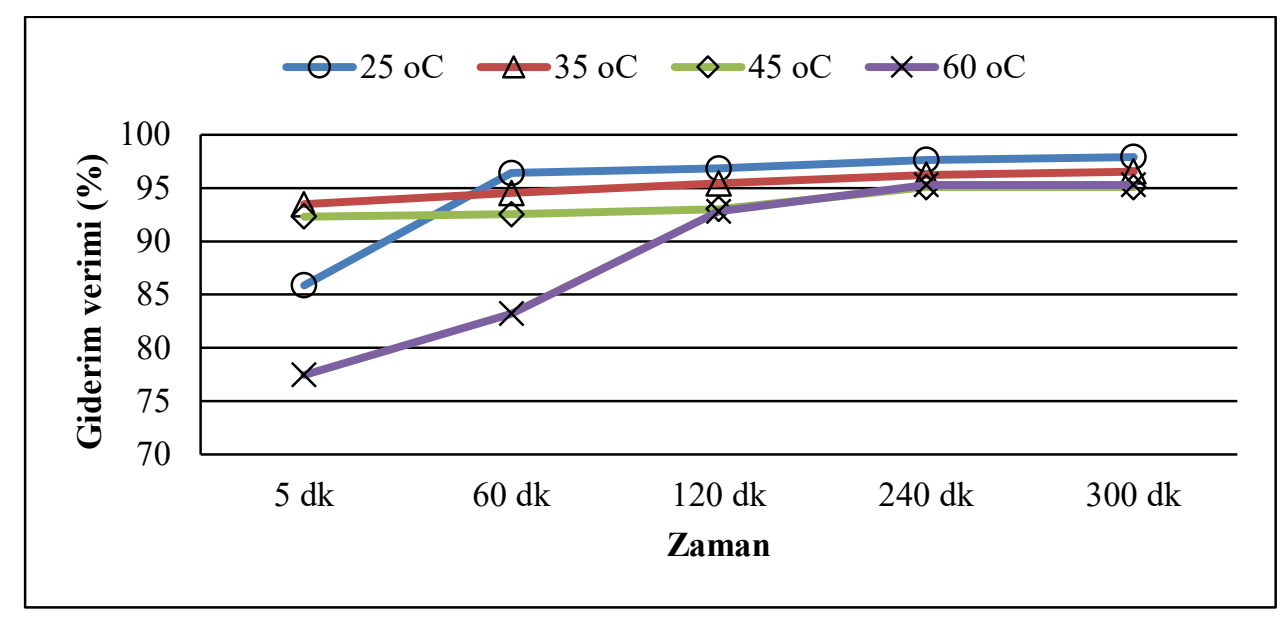

Şekil 14. DK için pH 2'de farklı sıcaklık ve sürelerin verime etkisi. 


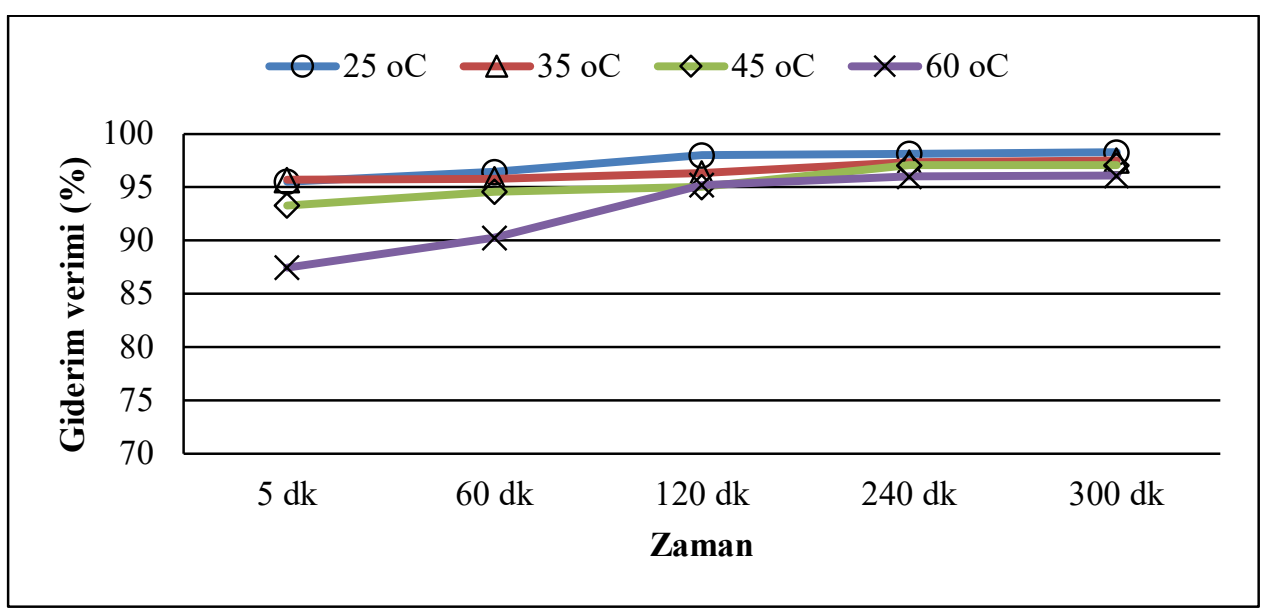

Şekil 15. DK için pH 4'de farklı sıcaklık ve sürelerin verime etkisi.

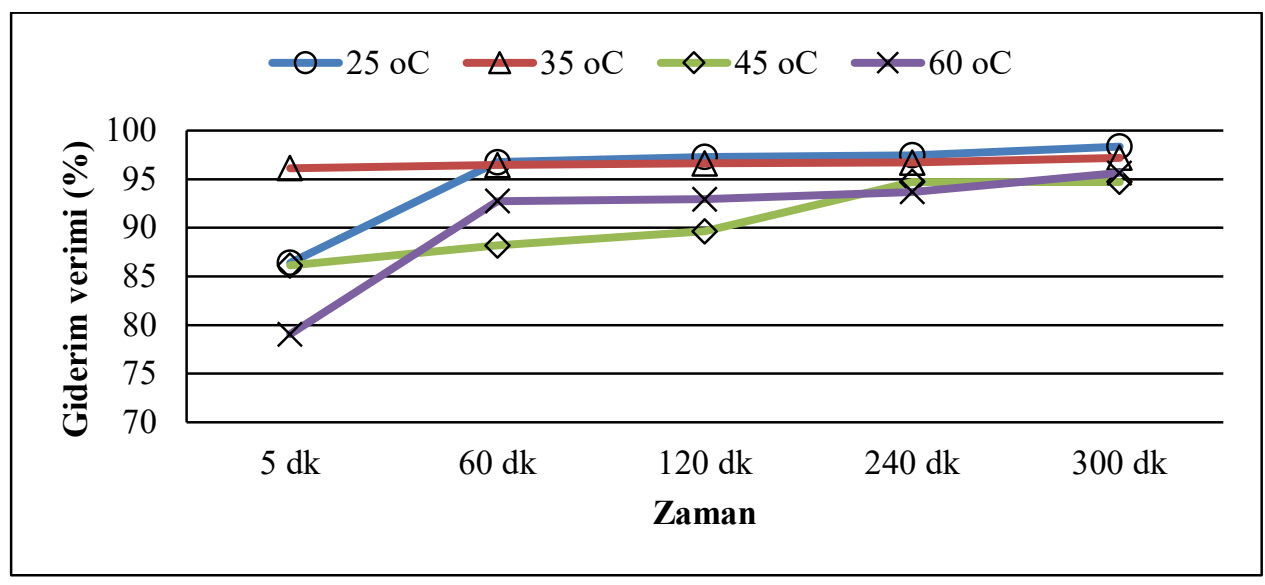

Şekil 16. DK için pH 6' da farklı sıcaklık ve sürelerin verime etkisi.

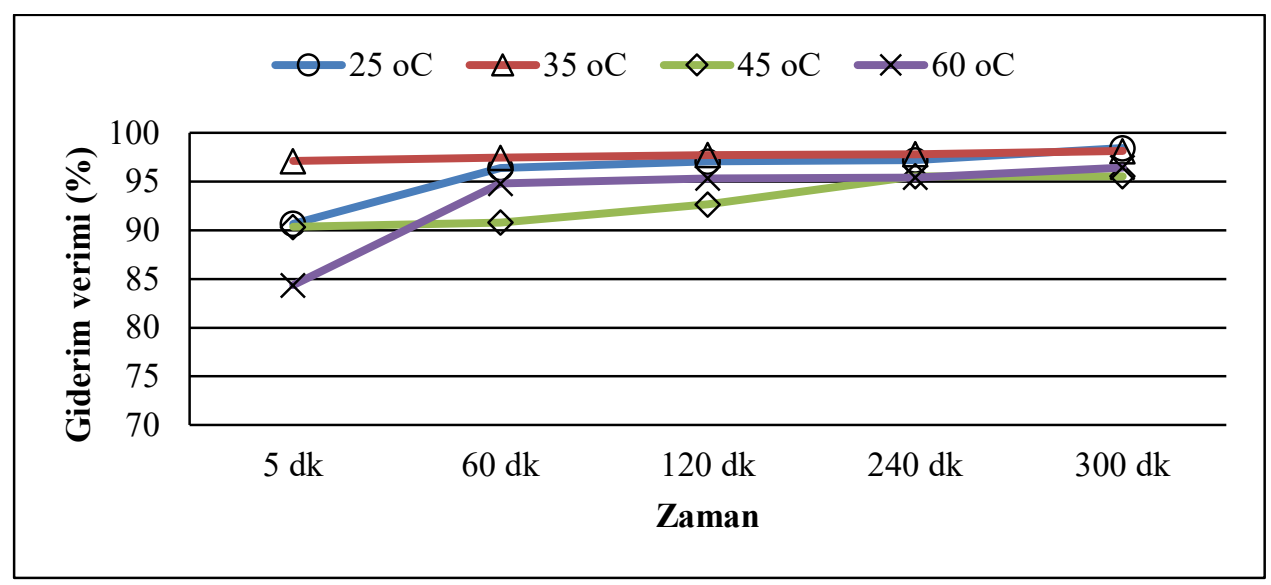

Şekil 17. DK için pH 8'de farklı sıcaklık ve sürelerin verime etkisi. 


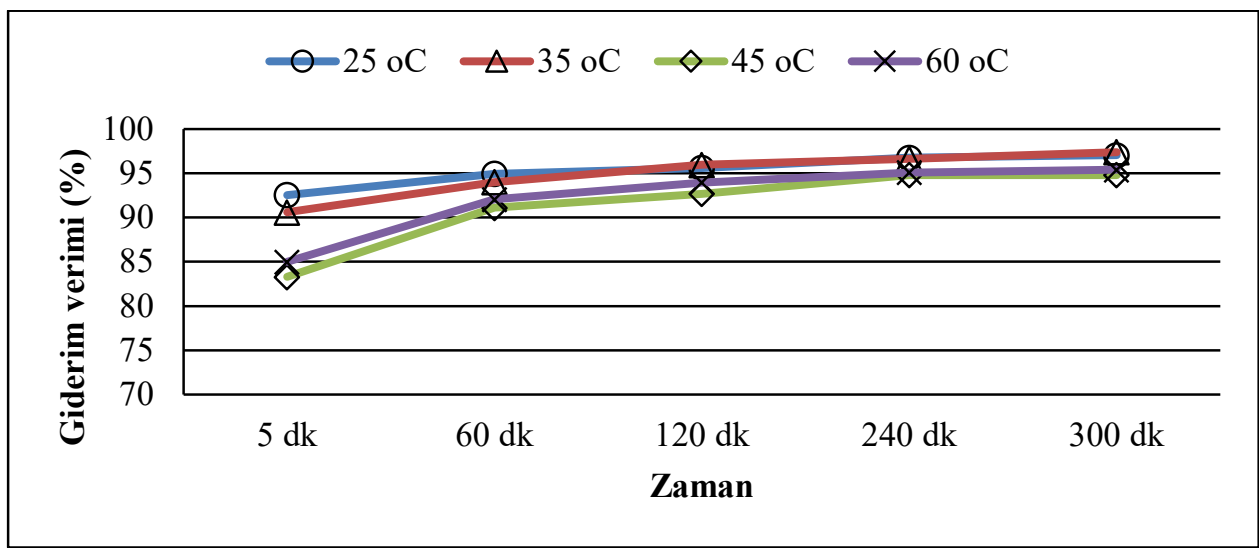

Şekil 18. DK için pH 10'da farklı sıcaklık ve sürelerin verime etkisi.

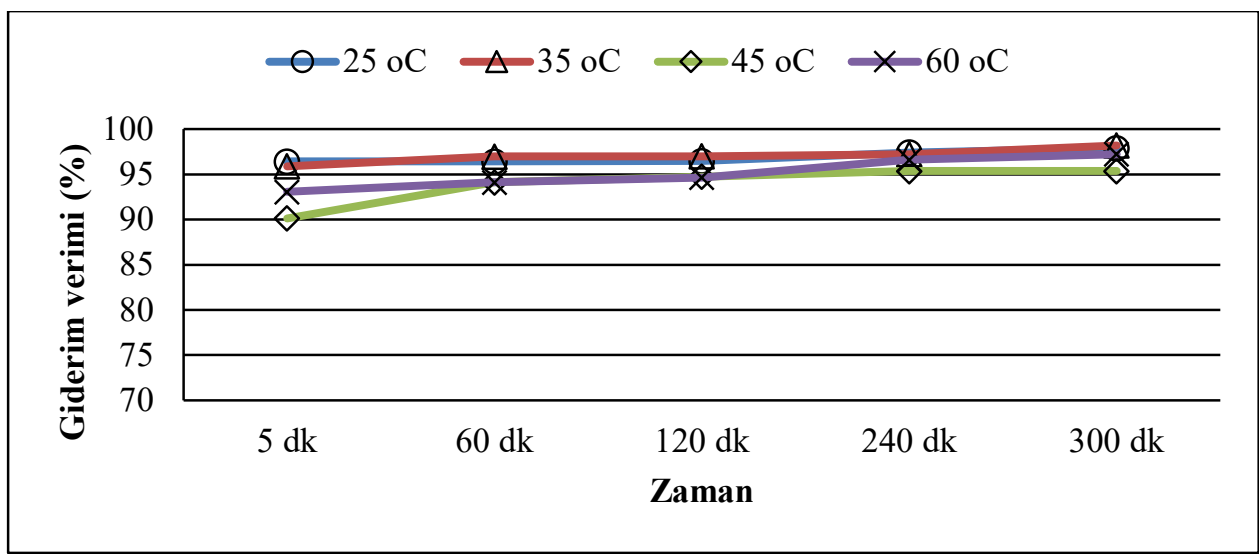

Şekil 19. DK için pH 12'de farklı sıcaklık ve sürelerin verime etkisi.

\subsection{Adsorpiyon izotermi}

\subsubsection{5 oC'deki adsorpsiyon izotermleri}

Adsorpsiyonun, çok güçlü bir homojen yüzeyde gerçekleştiğini Langmuir eşitliği ifade etmekte olsa da kimyasal heterojenliğin doğal adsorplayıcı maddelerin yapısında bulunması nedeniyle bu durum geçerliliğini yitirmektedir. Tablo 1'de görüldügü üzere izoterm ve sabitleri için en yüksek $\mathrm{R}^{2}$ değeri pH 12'de $\left(\mathrm{R}^{2}=0.98\right)$ elde edilmiştir. Bu nedenle de Langmuir İzoterminin DK ile bazik ortam koşulları için daha elverişli olduğu söylenebilir. Adsorbent ile adsorbat arasındaki adsorpsiyon enerjisi değerinin (b sabiti) $2.43 \times 10^{-4}-13.4 \times 10^{-4} \mathrm{~L} / \mathrm{mg}$ aralığında değiştiği, $\mathrm{pH}$ değerinin artmasıyla da adsorbent ile adsorbat arasındaki enerjinin de azaldığı belirlenmiştir. Langmuir İzoterminde $\mathrm{R}_{\mathrm{L}}$ değeri önemli bir karakteristik olup ayırma faktörü olarak kullanılmaktadır. $\mathrm{R}_{\mathrm{L}}$ değerinin optimum adsorpsiyon için $0<\mathrm{R}_{\mathrm{L}}<1$ arasında olması beklenir (URL-2, 2018). DK için $\mathrm{R}_{\mathrm{L}}$ değerlerinin tüm $\mathrm{pH}$ koşullarında 0.82-0.83 aralığında olması yani sıfır ile bir aralığında değişmesi dışarıdan enerjiye 
gereksinim duyulmadığını göstermektedir. Yapılan deneysel çalışmaların sonucu Langmuir İzotermine uygun olduğunu göstermektedir.

Tablo 1. Farklı pH değerlerindeki Langmuir İzotermi $\left(25^{\circ} \mathrm{C}\right)$.

\begin{tabular}{|c|c|c|c|c|}
\hline \multicolumn{4}{|c|}{ Doğal Kil } & \\
\hline \multirow[t]{2}{*}{$25^{\circ} \mathrm{C}$} & \multirow{2}{*}{$\begin{array}{l}\text { Langmuir } \\
\text { İzotermi } \\
\mathrm{R}^{2}\end{array}$} & \multicolumn{3}{|c|}{ Langmuir İzoterm Sabitleri } \\
\hline & & $\mathrm{b} \times 10^{-4}(\mathrm{~L} / \mathrm{mg})$ & $\mathrm{Q}_{\max }(\mathrm{mg} / \mathrm{g})$ & $\mathrm{R}_{\mathrm{L}}$ \\
\hline pH 2 & 0.91 & 13.4 & 156 & 0.82 \\
\hline pH 4 & 0.65 & 11.3 & 185 & 0.82 \\
\hline pH 6 & 0.72 & 7.25 & 285 & 0.82 \\
\hline pH 8 & 0.67 & 4.09 & 500 & 0.83 \\
\hline pH 10 & 0.91 & 6.99 & 294 & 0.83 \\
\hline pH 12 & 0.98 & 2.43 & 833 & 0.83 \\
\hline
\end{tabular}

Tablo 2'de verildiği üzere, DK için Freundlich İzotermine göre $25^{\circ} \mathrm{C}$ 'deki en yüksek $\mathrm{R}^{2}$ değeri pH 12'de $\left(\mathrm{R}^{2}=0.98\right)$ gözlenmiştir. Freundlich İzotermlerinde de Langmuir İzotermlerinde ki gibi bazik ortamın daha uygun olduğu tespit edilmiştir. DK için $\mathrm{K}_{\mathrm{f}}$ Freundlich sabitleri 4.92-4.95 mg/g arasında değişmektedir. Adsorpsiyonun yoğunluğuna ilişkin bilgi veren " $n$ " sabiti değerinin birden büyük olması adsorpsiyonun fiziksel olduğunu göstermektedir.

Tablo 2. Farklı $\mathrm{pH}$ değerlerindeki Freundlich İzotermi $\left(25^{\circ} \mathrm{C}\right)$.

\begin{tabular}{llll}
\hline & Doğal Kil & \\
\hline $\mathbf{2 5} \mathbf{0}^{\mathbf{C}}$ & Freundlich İzotermi & \multicolumn{2}{l}{ Freundlich İzoterm Sabitleri } \\
& $\mathrm{R}^{2}$ & $\mathrm{~K}_{\mathrm{f}}(\mathrm{mg} / \mathrm{g})$ & $\mathrm{n}$ \\
& & & \\
$\mathbf{p H ~ 2}$ & 0.98 & 4.93 & 48.07 \\
$\mathbf{p H ~ 4}$ & 0.90 & 4.92 & 42.91 \\
$\mathbf{p H ~ 6}$ & 0.95 & 4.92 & 57.47 \\
$\mathbf{p H ~ 8}$ & 0.92 & 4.93 & 78.12 \\
$\mathbf{p H ~ 1 0}$ & 0.97 & 4.94 & 72.46 \\
$\mathbf{p H ~ 1 2}$ & 0.99 & 4.95 & 128.20 \\
\hline
\end{tabular}

\subsubsection{5 oC sıcaklık için adsorpsiyon izotermleri}

Tablo 3'de görüldüğü üzere $\mathrm{DK}$ için en büyük $\mathrm{R}^{2}$ değeri $\mathrm{pH} 6$ ve $\mathrm{pH} 4$ 'de $\left(\mathrm{R}^{2}=0.98\right)$ gözlenmiştir. Buna göre DK için asidik ortamda Langmuir İzoterminin daha uygulanabilir olduğu sonucuna varılmaktadır. Adsorbent ile adsorbat arasında, adsorpsiyon enerjisi (b sabiti) $1.62 \times 10^{-4}$ $7.42 \times 10^{-4} \mathrm{~L} / \mathrm{mg}$ arasında değişim göstermektedir. Araştırmada $\mathrm{pH}$ koşullarının tamamında DK için 
$\mathrm{R}_{\mathrm{L}}$ değerlerinin (0.82-0.95) sıfır ile bir arasında değişim göstermesi adsorpsiyon için dışarıdan herhangi bir enerjiye ihtiyaç duyulmadığını kanıtlamaktadır. Yapılan analizler sonucunda adsorpsiyonun Langmuir İzotermine uyum gösterdiği belirlenmiştir.

Tablo 3. $35^{\circ} \mathrm{C}^{\prime}$ de Langmuir İzotermleri.

\begin{tabular}{lllll}
\hline \multicolumn{5}{c}{ Doğal Kil } \\
\hline $\mathbf{3 5}{ }^{\mathbf{0}} \mathbf{C}$ & $\begin{array}{l}\text { Langmuir } \\
\text { İzotermi }\end{array}$ & Langmuir İzoterm Sabitleri \\
& $\mathrm{R}^{2}$ & $\mathrm{~b} \times 10^{-4}(\mathrm{~L} / \mathrm{mg})$ & $\mathrm{Q}_{\max }(\mathrm{mg} / \mathrm{g})$ & $\mathrm{R}_{\mathrm{L}}$ \\
\hline pH 2 & 0.96 & 7.42 & 277 & 0.82 \\
pH 4 & 0.98 & 3.46 & 588 & 0.83 \\
pH 6 & 0.98 & 3.46 & 588 & 0.83 \\
pH 8 & 0.97 & 1.62 & 1250 & 0.83 \\
pH 10 & 0.86 & 7.84 & 263 & 0.83 \\
pH 12 & 0.90 & 2.03 & 1000 & 0.83 \\
\hline
\end{tabular}

DK için Freundlich İzotermlerine göre $35{ }^{\circ} \mathrm{C}$ sıcaklıktaki en yüksek $\mathrm{R}^{2}$ değeri pH 2, pH 4, pH 6 ve $\mathrm{pH} 8$ 'de $\left(\mathrm{R}^{2}=0.99\right)$ elde edilmiştir (Tablo 4$)$. Bu durum da DK için asidik ortamın uygun olduğuna işaret etmektedir. $K_{f}$ Freundlich sabitleri DK için 4.94-4.95 mg/g arasında değişim göstermektedir. $\mathrm{n}$ değerinin birden büyük olması adsorpsiyonun fiziksel gerçekleştiğinin kanıtıdır. Adsorpsiyonun Freundlich İzotermine uygun olmadığı söylenebilir.

Tablo 4. $35^{\circ} \mathrm{C}$ sıcaklık için Freundlich İzotermleri.

\begin{tabular}{|c|c|c|c|}
\hline \multicolumn{3}{|c|}{ Doğal Kil } & \\
\hline \multirow[t]{2}{*}{$35^{0} \mathrm{C}$} & \multirow{2}{*}{$\begin{array}{c}\text { Freundlich İzotermi } \\
\mathrm{R}^{2}\end{array}$} & \multicolumn{2}{|c|}{ Freundlich İzoterm Sabitleri } \\
\hline & & $\mathrm{K}_{\mathrm{f}}(\mathrm{mg} / \mathrm{g})$ & $\mathrm{n}$ \\
\hline pH 2 & 0.99 & 4.95 & 72.99 \\
\hline pH 4 & 0.99 & 4.94 & 107.52 \\
\hline pH 6 & 0.99 & 4.95 & 108.69 \\
\hline pH 8 & 0.99 & 4.95 & 156.25 \\
\hline pH 10 & 0.96 & 4.94 & 65.78 \\
\hline pH 12 & 0.97 & 4.95 & 133.33 \\
\hline
\end{tabular}

\section{Sonuçlar ve Öneriler}

Yapılan kesikli deneysel çalışmalar sonucunda; DK için temas süresinin artmasıyla birlikte adsorpsiyon kapasitesinin de belirli bir seviyeye kadar arttığı ve tüm koşullarda en yüksek giderim veriminin 300. dakikada gerçekleştiği tespit edilmiştir. DK kullanılarak renk giderimindeki en uygun 
ortam sıcaklığının pH 2, pH 4, pH 6 ve pH 8 koşullarında $25{ }^{\circ} \mathrm{C}$ olduğu, pH 10 ve pH 12 koşulunda ise $35{ }^{\circ} \mathrm{C}$ olduğu belirlenmiştir. Yüksek kapasiteli boya içeren atıksularda adsorpsiyon ile arıtım yapılırken sıcaklığın arttırılması yüksek maliyet anlamına gelmektedir. Ancak MGY-GE boyasının gideriminde kullanılan doğal killerin $25^{\circ} \mathrm{C}$ ve $35^{\circ} \mathrm{C}$ ortam sıcaklıklarında daha fazla renk giderimini sağlaması bu dezavantajı bertaraf etmektedir. Çalışmada kullanılan doğal kilin gerek adsorpsiyon sıcaklığını arttırmak için dışarıdan bir enerji gereksinimine duyulmaması gerekse de kullanılacak adsorbent miktarı (2.0 g) bakımından çok büyük avantaj sağlamaktadır. Deneysel çalışmalar sonucunda adsorpsiyonun Langmuir İzotermine daha uyumlu olduğu tespit edilmiştir. $25{ }^{\circ} \mathrm{C}$ ve $35^{\circ} \mathrm{C}$ ortam sciaklıklarında adsorbent ile adsorbat arasındaki enerjinin çok daha yüksek olduğu, pH'ın artması adsorbent ile adsorbat arasındaki enerjiyi azalttığı, adsorpsiyonun fiziksel adsorpsiyon olduğu ve dışarıdan bir enerjiye gereksinim olmadığı belirlenmiştir. Çalışmada kullanılan doğal kilin çözelti başlangıç pH'1 (7.06-7.18), katyon değişim kapasitesi (6 meq/100g, Amonyum Asetat Metodu) ile adsorpsiyon eğrileri birlikte değerlendirildiğinde Kaolinit kilinin kırmızı formu olduğu öngörülmektedir. Boyarmadde kullanılan endüstrilerde ortaya çıkan renkli atıksuların arıtılarak doğaya deşarj edilmesi günümüzde son derece önem kazanmıştır. Sonuç itibariyle; Nevşehir İlinde bol miktarda bulunan doğal kilin kullanılarak sürekli bir sistem ve doğal ortam sıcaklıklarında MGYGE boyalı atıksularının düşük maliyetli arıtımını sağlamak ekosistem açısından mümkün ve uygulanabilirdir.

\section{Yazarların Katkısı}

Tüm yazarlar çalışmaya eşit katkıda bulunmuştur.

\section{Çıkar Çatışması Beyanı}

Yazarlar arasında herhangi bir çıkar çatışması bulunmamaktadır.

\section{Araştırma ve Yayın Etiği Beyanı}

Yapılan çalışmada araştırma ve yayın etiğine uyulmuştur. 


\section{Kaynaklar}

Adeyemo, A.A., Adeoye, I.O., Bello, O.S. (2017). Adsorption of Dyes Using Different Types of Clay: A Review. Applied Water Science.7:543-568.

Doğan, M., Karaoğlu, M. H., Alkan, M. (2009). Adsorption Kinetics of Maxilon Yellow 4GL and Maxilon Red GRL Dyes on Kaolinite. J. Hazard. Mater., 165(1-3):1142-51.

Dogan, M., Alkan, M. (2010).Adsorption Kinetics of Methyl Violet Onto Perlite. Chemosphere, 50:517-528.

Elmoubarki, R., Mahjoubi, F.Z., Tounsadi, H., Moustadraf, J., Abdennouri, M., Zouhri, A., Albani, A. El, Barka, N. (2015). Adsorption Of Textile Dyes On Raw And Decanted Moroccan Clays: Kinetics, Equilibrium And Thermodynamics. Water Resources and Industry.9:16-29.

Freundlich, H.M.F. (1906). Over the adsorption in solution, J. Phys. Chem.57:385-471.

Fytıanos, K., Voudrias, E., Kokkalıs, E. (2000). Sorption-Desorption Behaviour of 2,4-Dichlorophenol by Marine Sediments. Chemosphere.40(1): 3-6.

Gürses, A., Yalcin, M., Dogar, C. (2002). Electrocoagulation of Some Reactive Dyes: A Statistical Investigation Of Some Electrochemical Variables. Waste Management. 22:491-499.

Gupta, V.K., Suhas, T.L. (2009). Application of Lowcost Adsorbents For Dye Removal-A Review. Journal of Environmental Management. 90:2313-2342.

Gok, O., Ozcan, A.S., Ozcan, A.(2010).Adsorption Behavior of A Textile Dye of Reactive Blue 19 From Aqueous Solutions Onto Modified Bentonite. Appl. Surf. Sci. 256:5439-5443.

Juang, R.S.,Wu, F.C., Tseng, R.L. (1997). The Ability of Activated Clay For The Adsorption of Dyes From Aqueous Solutions. Environmental Technology.18:525-531.

Kadhom, M., Albayati, N., Alalwan, H., \& Al-Furaiji, M. (2020). Removal of Dyes By Agricultural Waste. Sustainable Chemistry and Pharmacy, 16: 100259.

Kayacan, S.(2007). Removal of Dye Materials From Aqueous Solutions by Adsorption on Coals and Cokes, Yüksek Lisans Tezi, Ankara Üniversitesi, Fen Bilimleri Enstitüsü, Ankara.

Kalıpc1, E., Sahinkaya, S., Dortkol, M., Aras, S. (2016). Decolorization of Basic Textile Dyes Using A Novel Adsorbent Modification Method: Ultrasonic-Acid Modification. International Journal of Environmental Research. 10(1):31-40.

Kalıpc1, E. (2016). Removal of Methylene Blue From Aqueous Solution by Natural Olive Pomace Modified with Ultrasounds and Acid. Environment Protection Engineering. 42(3):5-17.

Kalıpc1, E. (2019). Adsorption of Cadmium (II) By Using Clays Modified With Ultrasound. International Journal of Global Warming.18(2):155-172.

Kaykıoğlu, G., Güneş, E. (2014). Pirinç Kabuğu Kullanılarak Üretilen Manyetik Nanopartiküller İle Sulu Çözeltilerden Renk Giderimi, NKUBAP.00.17.AR.12.07 Nolu BAP Projesi, Namık Kemal Üniversitesi, 1-55.

Kuleyin, A., Aydin, F. (2011). Removal of Reactive Textile Dyes (Remazol Brillant Blue R And Remazol Yellow) by Surfactant-Modified Natural Zeolite. Environmental Progress \& Sustainable Energy. 30(2):141-151.

Li, P., Gao, B., Li, A.,Yang, H. (2020). Evaluation of The Selective Adsorption of Silica-Sand/AnionizedStarch Composite For Removal of Dyes and Cupper (II) From Their Aqueous Mixtures. International journal of Biological Macromolecules. 149: 1285-1293.

Mingfei, Z., Peng, L.(2009).Adsorption of Methylene Blue From Aqueous Solutions by Modified Expanded Graphite Powder. Desalination, 249 (1):331-336, 2009.

Ngulube, T., Gumbo, J.R., Masindi, V., Maity, A. (2017). An Update On Synthetic Dyes Adsorption Onto Clay Based Minerals: A State-Of-Art Review. Journal of Environmental Management. 191:35-57.

Ouardi, M. El, Qourzal, S., Alahiane, S., Assabbane, A., Douch, J., (2015). Effective Removal of Nitrates Ions from Aqueous Solution Using New Clay as Potential Low-Cost Adsorbent. Journal of Encapsulation and Adsorption Sciences.5(4):178-190.

Öden, M., Küçükçongar, S. (2017). Removal of Dyes from Wastewater by Adsorption Using Modified Boron Enrichment Waste: Thermodynamic Criteria. Eurasian Journal of Environmental Research. 1(1):12-18.

Sun, Q., Yang, L. (2003).The Adsorption of Basic Dyes From Aqueous Solution on Modified Peat-Resin Particle. Water Research. 37:1535-1544.

Tara, N., Siddiqui, S. I., Rathi, G., Chaudhry, S. A., Asiri, A. M. (2020). Nano-Engineered Adsorbent For The Removal of Dyes From Water: A Review. Current Analytical Chemistry. 16(1):14-40. 
Uyar, G. (2012). A Low-Cost Adsorbent For Dye Removal:Methylene Blue Removal By AlginateMontmorillonite Hybride Beads. Yüksek Lisans Tezi, İstanbul Teknik Üniversitesi, Fen Bilimleri Enstitüsü.

Uysal, Y., Kereci, F.N. (2016).Tekstil Atık Külü İle Tekstil Atıksuyundan Renk Giderimi. Kahramanmaraş Sütçü İmam Üniversitesi Mühendislik Bilimleri Dergisi, 19(3):82-86.

URL-1:https://pubchem.ncbi.nlm.nih.gov/compound/Basic-Yellow-28, (Erişim Tarihi: 09 Mart 2021).

URL-2:http://www.rsc.org/suppdata/c5/ra/c5ra13004b/c5ra13004b1.pdf,2015.,(Erişim Tarihi:12 Mart 2018).

Weber, W., Digiano, F. (1996). Process Dynamics in Environmental Systems. Wiley, 1st Ed.:New York, USA.

Wu, J., Yang, J., Feng, P., Huang, G., Xu, C., Lin, B. (2020). High-Efficiency Removal Of Dyes From Wastewater By Fully Recycling Litchi Peel Biochar. Chemosphere, 246:125734.

Xia, L., Zhou, S., Zhang, C., Fu, Z., Wang, A., Zhang, Q., ... \& Xu, W. (2020). Environment-Friendly Juncus Effusus-Based Adsorbent With A Three-Dimensional Network Structure For Highly Efficient Removal of Dyes From Wastewater. Journal of Cleaner Production, 259, 120812. 